\title{
Study of Cardiac Arrhythmias in Acute Myocardial Infarction: A Hospital Based Study
}

\author{
Kidwai A
}

\begin{abstract}
Introduction: Coronary artery disease (CAD) remains the leading cause of death in the industrialized world. Majority of the deaths in $\mathrm{Ml}$ are attributed to the development of arrhythmias during periods of myocardial infarction. Identification of the type of arrhythmia is of therapeutic and prognostic importance. Materials and methods: This was a prospective observational study conducted at the department of Internal Medicine, Nepalgunj Medical College teaching hospital, Nepalgunj for a period of 12 months. 61 consecutive cases of myocardial infarction were included in the study on the basis of inclusion and exclusion criteria. Results and discussion: Out of the 61 cases that were included in the study. 45 (73.8\%) patients were above the age of 49 . There was only 1 patient below 29 years of age. The commonest risk factor was hypertension which was present in 48 (78.7\%) cases, followed by Diabetes Mellitus in $28(45.9 \%)$, smoking in $26(42.6 \%)$ and dyslipidemia in $12(19.7 \%)$ no. of subjects. Overall $41(67.2 \%)$ patients had anterior wall (anterior+anteroseptal+extensive anterior wall), 16(2.2\%) had inferior wall (inferior+inferolateral) and 4(6.6\%) had combined anterior and inferior wall myocardial infarction. Out of the 61 cases, arrhythmia was recorded in 55(90.2\%) cases whereas in 6(9.8\%) cases there was no evidence of any arrhythmia ${ }^{13}$. Ventricular premature complex was the commonest arrhythmia and was recorded in $48(78.7 \%)$ patients, followed by sinus tachycardia in 38(62.3\%) patients. Ventricular tachycardia occurred in $11(18 \%)$ and ventricular fibrillation was recorded in $4(6.6 \%)$ cases. Complete heart block was seen in $7(11.5 \%)$ cases. Conclusion: Most cases of myocardial infarction develop cardiac arrhythmias. Further studies on a larger scale are needed to further understand the magnitude and spectrum of this problem in the Nepalese population.
\end{abstract}

Key words: Acute coronary syndrome, cardiac arrhythmias, ST elevation myocardial infarction (STEMI), non ST elevation myocardial infarction (NSTEMI)

\section{INTRODUCTION}

Acute coronary syndrome (ACS) refers to a spectrum of conditions compatible with acute myocardial ischemia or infarction due to an abrupt reduction in coronary blood flow ${ }^{1}$. It consists of ST elevation myocardial infarction (STEMI), non ST elevation myocardial infarction (NSTEMI) and unstable angina (UA). Myocardial infarction (MI) can be diagnosed by clinical features like typical chest pain(angina) lasting for more than 30 minutes, typical electrocardiographic (E.C.G.) findings like ST segments elevation, depression and T wave inversion, elevated values of biochemical markers (troponin, creatine kinase) of myocardial necrosis (differentiating it from angina/ischemia), by detection of regional wall abnormality by imaging (echocardiography), or may be defined by pathology. It is a major cause of death and disability worldwide ${ }^{2}$. Despite the considerable progress in management over the recent years, coronary artery disease (CAD) remains the leading cause of death in the industrialized world. Asians, specially Indians show higher incidence, morbidity and mortality than other ethnic groups ${ }^{3}$. Similar studies in the Nepalese population are lacking, although similar findings may be expected due the similarities in population genetics, nutrition and lifestyle. Majority of the deaths in $\mathrm{MI}$ are attributed to the development of arrhythmias

\section{Address for correspondence:}

Dr. Aasim Kidwai

Department of Medicine

Nepalgunj Medical College Teaching Hospital

Nepalgunj, Banke, Nepal

Email: kidwai.aasim@gmail.com during periods of myocardial infarction ${ }^{4}$. In particular, ventricular fibrillation is attributable to $60 \%$ of all deaths related with acute myocardial infarction that occur within 1 st hour $^{5}$. The recent improvement in arrhythmia detection and treatment has had a key impact on the result of myocardial infarction. Some arrhythmias may be benign while some can be life threatening. There is strong connection between the site of infarct and type of arrhythmias. Sinus bradycardia, escape rhythms and heart blocks are typically associated with inferior wall myocardial infarction. Atrial and ventricular premature beats are more frequently seen in anterior wall myocardial infarction $^{6}$. With the advent of thrombolytic/reperfusion therapy, it was found that some rhythm disturbances in patients with acute myocardial infarction may be related to coronary artery reperfusion ${ }^{3}$. Identification of the type of arrhythmia is of therapeutic and prognostic importance as they can indicate either reperfusion, which is a good prognostic sign, or pathological arrhythmia, which can precipitate further ischemia, failure or shock ${ }^{7}$. This study was done to evaluate the incidence and profile of arrhythmias after acute myocardial infarction. This study was carried out at the department of Internal Medicine, Nepalgunj Medical College teaching hospital, Nepal. This study will help us to develop a better understanding of the incidence and profile of these arrhythmias in the Nepalese population.

\section{MATERIALS AND METHODS}

This was a hospital based observational study conducted at the deparment of Internal Medicine, Nepalgunj Medical College teaching hospital, Nepalgunj for a period of 12 months from 
November 2014 to November 2015. 61 consecutive cases of myocardial infarction were included in the study on the basis of inclusion and exclusion criteria.

\section{Inclusion criteria}

1. Age $>17$ years

2. Criteria for acute $\mathrm{MI}$ according to the universal definition of myocardial infarction ${ }^{2}$ :

Detection of a rise and/or fall of cardiac biomarker values [preferably cardiac troponin (cTn)] with at least one value above the 99th percentile upper reference limit (URL) and with at least one of the following:

a. Symptoms of ischaemia.

b. New or dynamic ST segments changes (elevation or depression), dynamic T wave changes.

c. Development of pathological Q waves in the ECG.

d. Imaging evidence of new loss of viable myocardium or new regional wall motion abnormality.

\section{Exclusion criteria}

1. Age $<18$ years.

2. Those who don't fulfill the inclusion criteria.

3. Chest pain due to other causes.

4. Those who do not give consent.

5. Patients who have arrhythmia before the onset of $\mathrm{MI}$ on the basis of history and documentation.

6. Patients who had to be referred to higher centers due to complications

7. Patients who wanted to go to a higher center after primary treatment.

Thorough history, clinical examination and relevant investigations including E.C.G., Echocardiography, Cardiac enzymes and other routine investigations were done in all cases. Informed consent was taken from all the patients or their guardians. All the patients were managed according to the standard protocol and guidelines of management of myocardial infarction and were shifted to the critical care unit for observation. Patients with STEMI who came within 12 hours of onset of chest pain and had no contraindication, received reperfusion therapy with Inj. Streptokinase 1.5 M.U. given slowly over one hours under cardiac monitoring. Cardiac monitors were attached to every patient and vitals were monitored closely. Monitoring and recording of any arrhythmia during stay of the patient in the critical care was done. Total no. and types of arrhythmia were recorded as such that if a single patient had two different arrhythmias then both were recorded as separate events. The results were analyzed using Microsoft Excel 2013.

\section{RESULT}

A total of 61 cases were included in the study. The age distribution was as follows:

\begin{tabular}{|c|c|c|}
\hline Age Group (yrs.) & No. of patients & \% \\
\hline $18-29$ & 1 & $1.6 \%$ \\
\hline $29-39$ & 4 & $6.6 \%$ \\
\hline $39-49$ & 11 & $18.0 \%$ \\
\hline $49-59$ & 23 & $37.7 \%$ \\
\hline $59-70$ & 18 & $29.5 \%$ \\
\hline$>70$ & 4 & $6.6 \%$ \\
\hline
\end{tabular}

Table I : Age distribution

\begin{tabular}{|c|c|c|}
\hline Sex & No. of patients & \% \\
\hline Males & 48 & $78.7 \%$ \\
\hline Females & 13 & $21.3 \%$ \\
\hline
\end{tabular}

Table II : Sex Distribution

\begin{tabular}{|l|c|c|}
\hline Risk factor & No. of patients & \% \\
\hline Diabetes Mellitus & 28 & $45.9 \%$ \\
\hline Hypertension & 48 & $78.7 \%$ \\
\hline Smoking & 26 & $42.6 \%$ \\
\hline Dyslipidemia & 12 & $19.7 \%$ \\
\hline 2 or more risk factors & 23 & $37.7 \%$ \\
\hline No risk factors & 7 & $11.5 \%$ \\
\hline
\end{tabular}

Table III : Risk factors

\begin{tabular}{|l|c|c|}
\hline Site & No. of patients & \% \\
\hline Anterior & 9 & $14.8 \%$ \\
\hline Anteroseptal & 25 & $40.9 \%$ \\
\hline Lateral & 0 & $0 \%$ \\
\hline Extensive anterior & 7 & $11.5 \%$ \\
\hline Inferior & 14 & $22.9 \%$ \\
\hline Inferolateral & 2 & $3.3 \%$ \\
\hline Anterior + inferior & 4 & $6.6 \%$ \\
\hline
\end{tabular}

Table IV : Site of Infarction

\begin{tabular}{|c|c|c|}
\hline Arrhythmias & No. of patients & \% \\
\hline Present & 55 & $90.2 \%$ \\
\hline Absent & 6 & $9.8 \%$ \\
\hline
\end{tabular}

Table V : Incidence of arrhythmias 


\begin{tabular}{|l|c|c|}
\hline Type of arrhythmia & $\begin{array}{c}\text { No. of } \\
\text { patients }\end{array}$ & \% \\
\hline Sinus tachycardia & 38 & $62.3 \%$ \\
\hline Sinus bradycardia & 12 & $19.6 \%$ \\
\hline Atrial premature complex & 6 & $9.8 \%$ \\
\hline Supraventricular tachycardia & 1 & $1.6 \%$ \\
\hline Junctional rhythm & 1 & $1.6 \%$ \\
\hline Ventricular premature complex & 48 & $78.7 \%$ \\
\hline Ventricular tachycardia & 11 & $18.0 \%$ \\
\hline Ventricular fibrillation & 4 & $6.6 \%$ \\
\hline 1st degree AV block & 3 & $4.9 \%$ \\
\hline 2nd dedgree AV block & 2 & $3.3 \%$ \\
\hline $\begin{array}{l}\text { 3rd degree AV block } \\
\text { (complete, CHB) }\end{array}$ & 7 & $11.5 \%$ \\
\hline
\end{tabular}

Table VI : Types of arrhythmias

The most no. of patients were between the age group $49-59$ years which was $23(37.7 \%) .45(73.8 \%)$ patients were above the age of 49 . There was only 1 patient below 29 years of age.

The commonest risk factor identified was hypertension which was present in $48(78.7 \%)$ cases. 7 patients had no identifiable risk factor. 23 patients had 2 or more risk factors. 26 (42.6\% )patients were smokers.

Anterior infarction ( anterior+anteroseptal+extensive anterior) was seen in a total of $41(67.2 \%)$ patients and inferior in $16(26.2 \%)$. Combined anterior and inferior infarction was seen in $4(6.6 \%)$ patients.

Arrhythmia was recorded in $55(90.2 \%)$ cases. 34 patients developed more than one type of arrhythmia at different points of time.

\section{DISCUSSION}

Out of the 61 cases $45(73.8 \%)$ were above 49 years of age and only 1 patient was below 29 years. This is similar to findings published by Lerner DJ et al in a follow up study of the Framingham population. ${ }^{8}$ The findings are similar to the results of studies done by various Indian researchers ${ }^{9,10,11}$. There was a predominance of male patients, which were $4878.7 \%$ ), with only $13(21.3 \%)$ females. This is also similar to the results published by Yadav P et al and Singh PS et al in their studies ${ }^{9,10}$. The commonest risk factor was hypertension which was present in 48 (78.7\%) cases, followed by Diabetes Mellitus in $28(45.9 \%)$, smoking in $26(42.6 \%)$ and dyslipidemia in $12(19.7 \%)$ no. of subjects. 23 patients had more than one risk factor and in 7 cases no risk factor could be identified.

Localization of the site of infarction was done by typical infarction patterns on ECG leads as per standard references ${ }^{12}$. The most common site of myocardial infarction was anteroseptal which was diagnosed in 25(40.9\%) subjects.
Overall 41(67.2\%) patients had anterior wall (anterior+anteroseptal+extensive anterior wall), 16(2.2\%) had inferior wall ( inferior+inferolateral) and $4(6.6 \%)$ had combined anterior and inferior wall myocardial infarction. Out of the 61 cases arrhythmia was recorded in 55(90.2\%) cases whereas in $6(9.8 \%)$ cases no evidence of any arrhythmia. This result is similar to report published by Aufderheide who reported a incidence of $90 \%{ }^{13}$. Ventricular premature complex was the commonest arrhythmia which was recorded in $48(78.7 \%)$ of patients. This result is similar to the result reported by Bigger JT et al and Volpi A et al in their respective studies which was between $80 \%$ to $90 \%{ }^{14,15}$. Sinus tachycardia was the second most common arrhythmia which was seen in 38(62.35) cases. The incidence of sinus tachycardia has been reported between $31-68 \%$ in various studies ${ }^{16-19}$. Ventricular tachycardia occurred in $11(18 \%)$ and ventricular fibrillation was recorded in $4(6.6 \%)$ cases, all of which had anterior wall myocardial infarction. Complete Heart Block was seen in $7(11.5 \%)$ cases. This result is slightly higher than reported by most studies which report it between 3.2-6.5\% ${ }^{18-24}$. All these patients had inferior myocardial infarction which is similar to the data published by most studies ${ }^{19,21-24}$. First degree AV block was seen in 3(4.9\%) patients and second degree in 2(3.3\%) patients, both of which were Mobitz type II. From this data it can be suggested that drugs that can precipitate AV blocks should be avoided in inferior myocardial infarction like beta blockers. On the other hand they should be used whenever possible in anterior myocardial infarction as they can prevent ventricular arrhythmias and may help in reducing mortality.

\section{CONCLUSION}

Most cases of myocardial infarction develop cardiac arrhythmias. In our study 55(90.2\%) of patient developed arrhythmias. Ventricular premature complex was the commonest arrhythmia observed, followed by sinus tachycardia. Heart blocks were more commonly seen in inferior myocardial infarction and complete heart block was only seen in inferior myocardial infarction, though the incidence was higher than other reported in other studies. ${ }^{18-24}$ Ventricular tachycardia and fibrillation only occurred in anterior myocardial infarction. It can be concluded from this study that arrhythmias in myocardial infarction are a common complication in the Nepalese population and incidence is similar to other Asian and western populations. A higher incidence of complete heart block was noted compared to other studies which was related to the higher incidence of inferior myocardial infarction in our study group. One limitation of our study was the small sample size. More studies on a larger scales are needed to further understand the magnitude and spectrum of this problem in the Nepalese population.

\section{REFERENCES}

1. Amsterdam EA, etal. 2014 ACC/AHA guideline for the management of patients with non-ST-elevation acute coronary syndrome: a report of the American College of Cardiology/ 
American Heart Association Task Force on Practice Guidelines. Circulation. 2014;000:000-000

2. Kristian Thygesen etal. Third universal definition of myocardial infarction. European Heart Journal. 2012; 33:2551-2567

3. Enas EA, Dhawan J, Petkar S. Coronary artery diseases in Asian Indians: lessons learnt and the role of lipoprotein a. Indian Heart J. 1996;49:25-34

4. Fabijanic D, Culic V, Bozic I et al. Gender differences in in-hospital mortality and mechanisms of death after the first acute myocardial infarction. Ann Saudi Med. 2006; 26(6):455-60.

5. Podrid PJ. Ventricular arrhythmias after acute myocardial infarction, incidence and clinical features. BJMU.2006;26:1-8.

6. John KA. A history of cardiac arrhythmias. 2 nd ed. Chapter I. In: arrhythmias. WB Saunders Company;2000.

7. Kostis JB, etal. Prognostic significance of ventricular ectopic activity in survivors of acute myocardial infarction. J Am Coll Cardiol 1987; 10:231-42

8. Lerner DJ, Kannel WB. Pattern of coronary heart disease morbidity and mortality in sexes: a 26-year follow of the Framingham population. Am Heart J. 1986;111:383

9. Singh PS et al. Clinical profile and risk factors in acute coronary syndrome. Journal, Indian Academy of Clinical Medicine. 2013April-June; 14(2):130-2

10. Yadav $p$ et al. clinical profile \& risk factors in acute coronary syndrome. National Journal of Community Medicine. 2010; 1(2):150-152.

11. Siwach S.B. et al. Profile of young acute myocardial infarction in Haryana. J Assoc Physicians India.1998 May; 46(5): 424-6.

12. Rowlands D.J. Clinical Electrocardiography, New York: Gower Medical Publishing. 1991;114-504.

13. Aufderheide TP. Arrhythmias associated with acute myocardial infarction and thrombolysis. Emerg Med Clin North Am 1998;16:583-600

14. Bigger JT, Dresdale RJ, Heissenbattel RH, Weld FM, Wit Al. Ventricular arrhythmias in ischemic heart disease: mechanism, prevalence, significance and management. Prog Cardiovasc Dis. 1977; 19:255-300

15. Volpi A, Cavalli A, Franzosi MG, Maggioni A, Mauri F, Santoro E. The GISSI investigators. One year prognosis of primary ventricular fibrillation complicating acute myocardial infarction Am J Cardiol. 1989;63(17):1174.

16. Jacob et al. Study of incidence and pattern of arrhythmias complicating acute myocardial infarction correlating it to the site of infarct. Abstract: Joint Annual Conference of Association of Physicians of India and Cardiological Society of India: South Zone.1992;150-98.

17. Julian D.G, P.A. Valentine and G.C. Miller. Disturbances of Rate, Rhythm and conduction in acute myocardial infarction. Am.J. Me. 1964 December; 37(6): 915-27.

18. Bahl A. L., H.B. Lal and P.N. Dharwad. Arrhythmias complicating Acute myocardial infarction. J Indian Med Assoc. 1969 Dec 1;53(11):534-8

19. Sangita Rathod et al. Study of various cardiac arrhythmias in patients of acute myocardial infarction: Int Arch Inte Med. 2014 December; 1(4):32-41.

20. Mohit J Shah et al. A Study of 100 Cases of Arrhythmias in First Week of Acute Myocardial Infarction in Gujarat, A High Risk and Previously Undocumented Population. J Clin Diagn Res. 2014 Jan; 8(1): 58-61.

21. Shimal Khan et al. In-hospital outcome of patients having Acute myocardial infarction with and Without streptokinase; Gomal
Journal of Medical Sciences. 2009 July-December; 7(2):96-100.

22. Sharma S.K. et al. Incidence and nature of cardiac arrhythmias in cases of acute myocardial infarction in relation to some major coronary risk factors. J Assoc Physicians India. 1986 Jun; 34(6):413-5.

23. Nigam P.D. et al. Complications of acute myocardial infarction during first three weeks. Indian Heart J. 1968 Apr; 20(2):157-64.

24. Imperial E.S, R. Carballo and H.A. Zimmerman. Disturbances of Rate, Rhythm and conduction in acute myocardial infarction. Am J. Cardiol.1960 January; 5(1):24-9. 